Supporting Information

\title{
Lipophilic Vitamin E Diffusion through Bicontinuous Microemulsions
}

Dai Kato ${ }^{1,{ }^{*}}$, Johtaro Yamamoto ${ }^{1, \ddagger}$, Yoshio Suzuki ${ }^{1}$, Tomoyuki Kamata ${ }^{1}$, Hinako Hashimoto $^{1,2}$ and Masashi Kunitake ${ }^{2}$

${ }^{1}$ Health and Medical Research Institute, National Institute of Advanced Industrial Science and Technology (AIST), 1-1-1 Higashi, Tsukuba 305-8566, Japan.

${ }^{2}$ Graduate School of Science and Technology and Institute of Industrial Nanomaterials, Kumamoto University, 2-39-1 Kurokami, Kumamoto 860-8555, Japan.

*dai.kato@aist.go.jp

\section{Table of Contents}

Scheme S1. Synthesis of VE-BODIPY . S-2

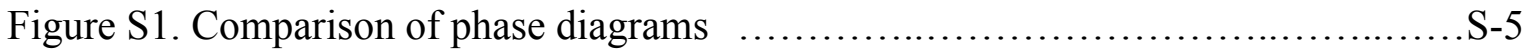

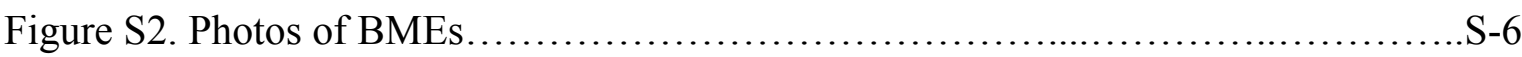

Figure S3. Transmittance of BME................................................

Figure S4. Cole-Cole plots..........................................................

Figure S5. Experimental setup for FCS measurements............................. 


\section{Synthesis of VE-BODIPY.}

The synthetic route of our VE-BODIPY is illustrated in Scheme S1.

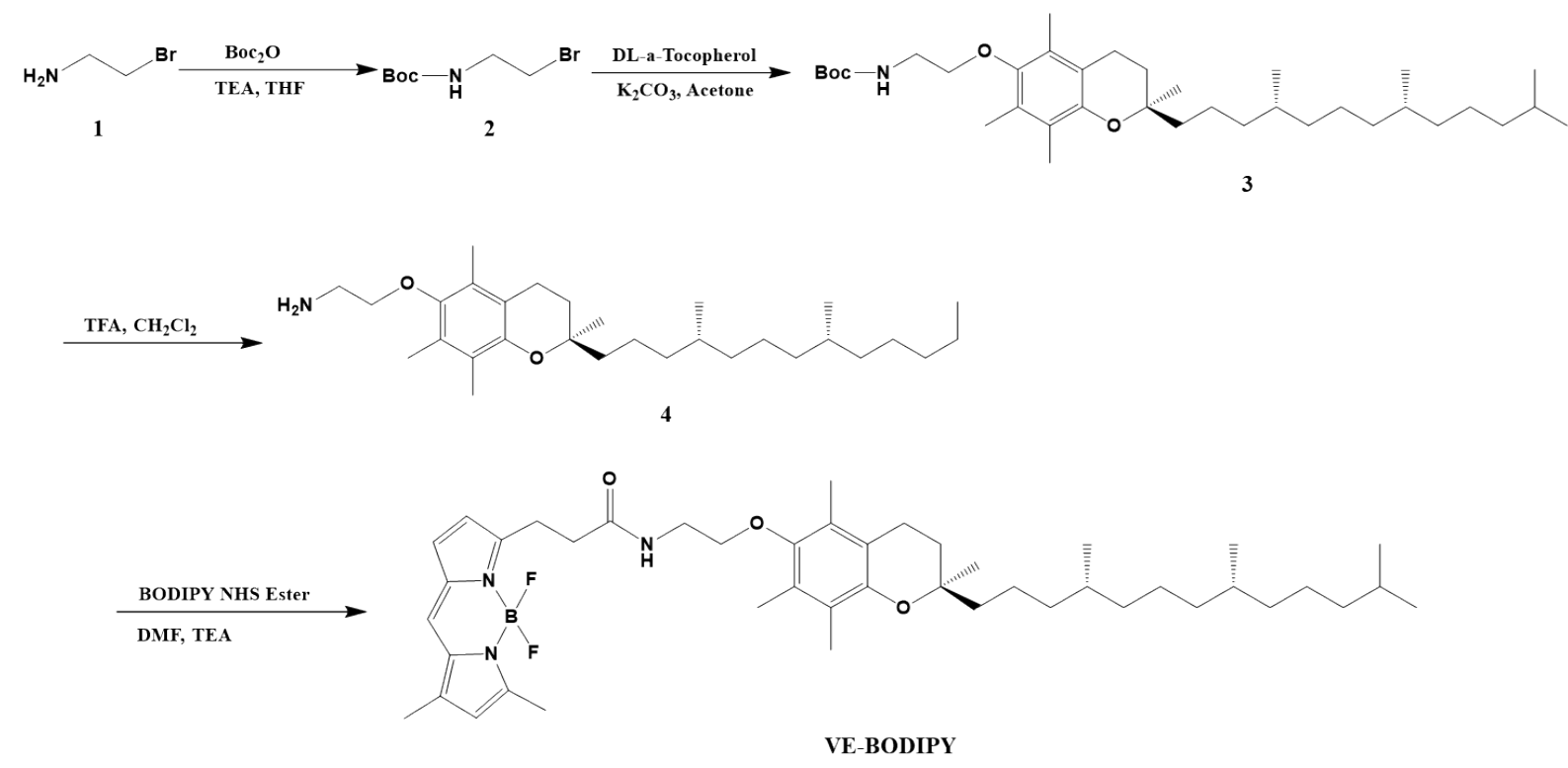

Scheme S1. VE-BODIPY synthesis method.

Methods are detailed below;

tert-butyl (2-bromoethyl)carbamate (2).

Di-tert-butyl dicarbonate $(3.3 \mathrm{~g}, 14.5 \mathrm{mmol})$ was added to a solution of 2-bromoethylamine hydrobromide (3.0 g, $14.5 \mathrm{mmol})$ and triethylamine $(3.0 \mathrm{~g}, 29.1 \mathrm{mmol})$ in THF $(100 \mathrm{~mL})$, and stirred at room temperature for 12 hours in a nitrogen atmosphere. The THF was then removed, the residue was dissolved in ethyl acetate, washed with brine, and dried over $\mathrm{Na}_{2} \mathrm{SO}_{4}$. The solvent was evaporated in vacuo, and the product was purified by column chromatography $\left(\mathrm{SiO}_{2}, n\right.$-hexane $\left.: \mathrm{AcOEt}=4: 1 \mathrm{v} / \mathrm{v}\right)$ to give an oil compound.

Yield: $92 \%$

${ }^{1} \mathrm{H}$ NMR $\left(\mathrm{CDCl}_{3}, 400 \mathrm{MHz}\right.$, r.t., TMS, $\left.\delta / \mathrm{ppm}\right) 1.45$ (9H, s), 3.44-3.47 (2H, m), 3.52-3.54 (2H, $\mathrm{m}), 4.96(1 \mathrm{H}, \mathrm{t})$.

tert-butyl $\quad(2-(((R)-2,5,7,8$-tetramethyl-2-((4R,8R)-4,8,12-trimethyltridecyl)chroman-6yl)oxy)ethyl)carbamate (3) 
To a solution of tert-butyl (2-bromoethyl)carbamate $(0.3 \mathrm{~g}, 1.1 \mathrm{mmol})$ in acetone $(60 \mathrm{~mL})$, vitamin $\mathrm{E}(0.5 \mathrm{~g}, 1.1 \mathrm{mmol})$ and $\mathrm{K}_{2} \mathrm{CO}_{3}(0.7 \mathrm{~g}, 4.9 \mathrm{mmol})$ were added, and the reaction mixture was refluxed for 12 hours in a nitrogen atmosphere. After the solvent was removed, the residue was dissolved in ethyl acetate, washed with brine, and dried over $\mathrm{Na}_{2} \mathrm{SO}_{4}$. The solvent was evaporated in vacuo, and the product was purified by column chromatography $\left(\mathrm{SiO}_{2}, n\right.$-hexane $: \mathrm{AcOEt}=2: 1 \mathrm{v} / \mathrm{v}$ ) to give an oil compound.

Yield: $74 \%$

${ }^{1} \mathrm{H}$ NMR $\left(\mathrm{CDCl}_{3}, 400 \mathrm{MHz}\right.$, r.t., TMS, $\left.\delta / \mathrm{ppm}\right)$ 0.85-0.90 (12H, m), 1.06-1.12 (7H, m), 1.21$1.28(10 \mathrm{H}, \mathrm{m}), 1.33-1.42(4 \mathrm{H}, \mathrm{m}) 1.46(9 \mathrm{H}, \mathrm{s}), 1.50-1.56(4 \mathrm{H}, \mathrm{m}), 1.76-1.85(2 \mathrm{H}, \mathrm{m}), 2.13(6 \mathrm{H}$, s), $2.18(3 \mathrm{H}, \mathrm{s}), 2.62(2 \mathrm{H}, \mathrm{t}), 3.46-3.48(2 \mathrm{H}, \mathrm{m}), 3.53-3.55(2 \mathrm{H}, \mathrm{m}), 4.98(1 \mathrm{H}, \mathrm{t})$.

\section{2-(((R)-2-((4R,8R)-4,8-dimethyltridecyl)-2,5,7,8-tetramethylchroman-6-yl)oxy)ethan-1-}

amine (4)

To a solution of tert-butyl (2-(((R)-2,5,7,8-tetramethyl-2-((4R,8R)-4,8,12trimethyltridecyl)chroman-6-yl)oxy)ethyl)carbamate $(1.0 \mathrm{~g}, 1.74 \mathrm{mmol})$ in dichloromethane $(25 \mathrm{~mL})$ on an ice bath, trifluoroacetic acid $(15 \mathrm{~mL})$ was added, and the reaction mixture was stirred for 2 hours. After the solvent was removed in vacuo, the residue was dissolved in $\mathrm{H}_{2} \mathrm{O}$, and alkalized with aq. $\mathrm{NH}_{3}$. The resulting mixture was extracted with dichloromethane, and the combined organic phases were washed with brine and dried over $\mathrm{Na}_{2} \mathrm{SO}_{4}$. After the solvent was removed in vacuo, the product was obtained quantitatively, and was used for the next reaction without further purification.

Yield: $97 \%$

${ }^{1} \mathrm{H} \mathrm{NMR}\left(\mathrm{CDCl}_{3}, 400 \mathrm{MHz}\right.$, r.t., TMS, $\left.\delta / \mathrm{ppm}\right)$ 0.86-0.91 (12H, m), 1.07-1.13 (7H, m), 1.22$1.27(10 \mathrm{H}, \mathrm{m}), 1.33-1.43(4 \mathrm{H}, \mathrm{m}), 1.51-1.57(4 \mathrm{H}, \mathrm{m}), 1.75-1.84(2 \mathrm{H}, \mathrm{m}), 2.12(6 \mathrm{H}, \mathrm{s}), 2.19(3 \mathrm{H}$, s), $2.61(2 \mathrm{H}, \mathrm{t}), 3.47-3.49(2 \mathrm{H}, \mathrm{m}), 3.53-3.56(2 \mathrm{H}, \mathrm{m})$.

\section{3-(5,5-difluoro-7,9-dimethyl-5H-4 $\lambda^{4}, 5 \lambda^{4}$-dipyrrolo[1,2-c:2',1'-f] [1,3,2]diazaborinin-3-yl)-} N-(2-(((R)-2,5,7,8-tetramethyl-2-((4R,8R)-4,8,12-trimethyltridecyl)chroman-6-

\section{yl)oxy)ethyl)propenamide (VE-BODIPY)}

BODIPY ${ }^{\mathrm{TM}}$ FL NHS ester $(5.0 \mathrm{mg}, 1.8 \mathrm{mmol})$ was added to a solution of 2-(((R)-2-((4R,8R)4,8-dimethyltridecyl)-2,5,7,8-tetramethylchroman-6-yl)oxy)ethan-1-amine (7.0 mg, $1.8 \mathrm{mmol})$ and triethylamine $(1.0 \mathrm{mg}, 1.8 \mathrm{mmol})$ in dry THF $(0.5 \mathrm{~mL})$ and DMF $(0.5 \mathrm{~mL})$, and the reaction mixture was stirred for 12 hours at $4{ }^{\circ} \mathrm{C}$. The solvent was evaporated in vacuo, and the residue was dissolved in AcOEt, washed with water, and dried over $\mathrm{Na}_{2} \mathrm{SO}_{4}$. After the solvent was removed, the product was purified by column chromatography $\left(\mathrm{SiO}_{2}, \mathrm{CHCl}_{3}: \mathrm{MeOH}=10: 1\right.$ 
$\mathrm{v} / \mathrm{v})$ to give a brown solid.

Yield: $85 \%$

${ }^{1} \mathrm{H}$ NMR $\left(\mathrm{CDCl}_{3}, 400 \mathrm{MHz}\right.$, r.t., TMS, $\left.\delta / \mathrm{ppm}\right)$ 0.87-0.92 (12H, m), 1.06-1.11 (7H, m), 1.21$1.26(10 \mathrm{H}, \mathrm{m}), 1.31-1.42(4 \mathrm{H}, \mathrm{m}), 1.50-1.55(4 \mathrm{H}, \mathrm{m}), 1.76-1.85(2 \mathrm{H}, \mathrm{m}), 2.13(6 \mathrm{H}, \mathrm{s}), 2.14(6 \mathrm{H}$, s), $2.18(3 \mathrm{H}, \mathrm{s}), 2.41(2 \mathrm{H}, \mathrm{t}), 2.51(2 \mathrm{H}, \mathrm{t}), 2.61(2 \mathrm{H}, \mathrm{t}), 3.46-3.48(2 \mathrm{H}, \mathrm{m}), 3.54-3.57(2 \mathrm{H}, \mathrm{m})$, $5.65(1 \mathrm{H}, \mathrm{s}), 6.25(1 \mathrm{H}, \mathrm{d}), 7.48(1 \mathrm{H}, \mathrm{s}), 7.86(1 \mathrm{H}, \mathrm{d}), 8.01(1 \mathrm{H}, \mathrm{t})$. 


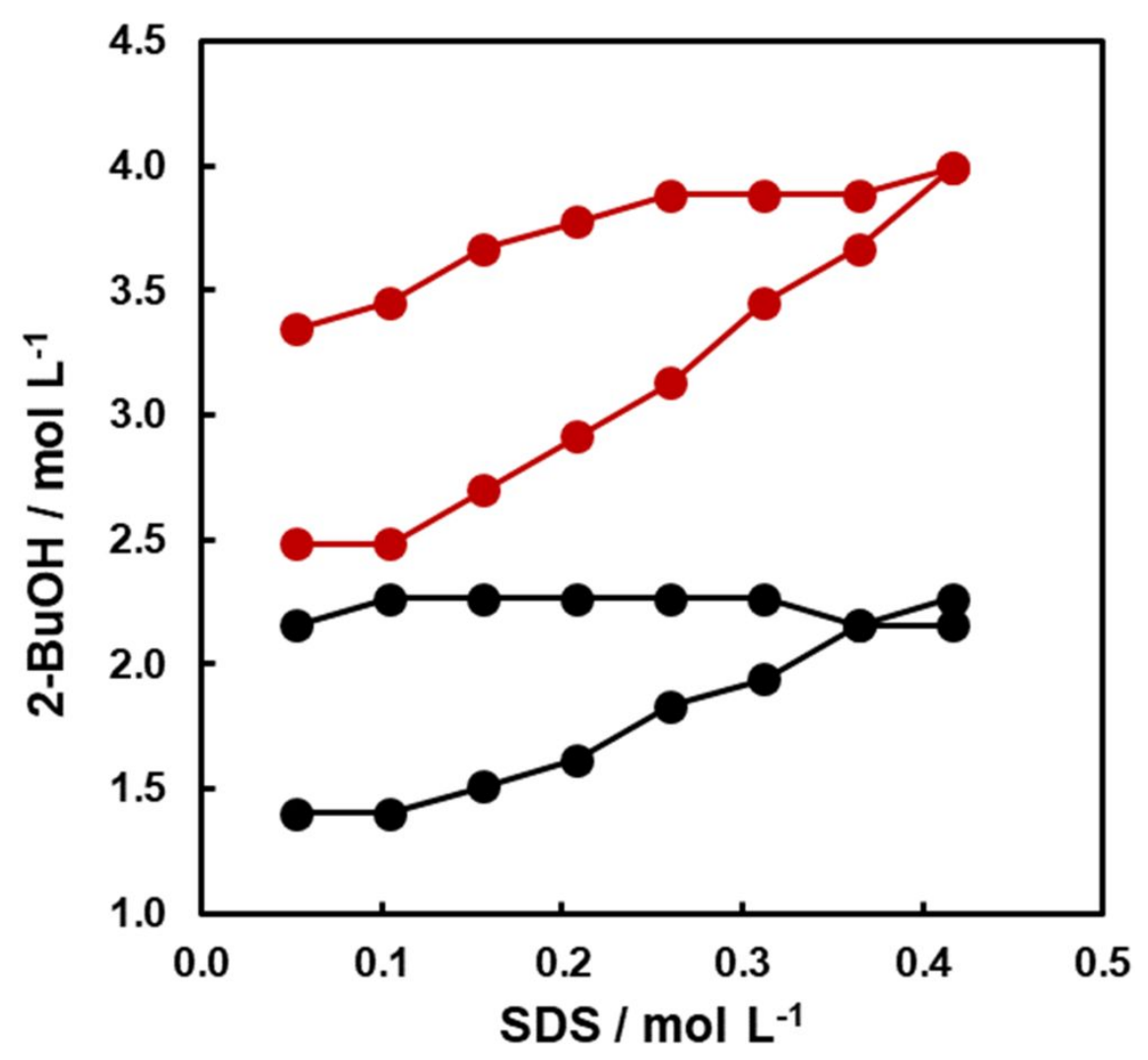

Figure S1. Comparison of phase diagrams of toluene-based BME (black) and heptanebased BME (red). The plot of the heptane-based-BME is the same as that in Figure 1(a). 

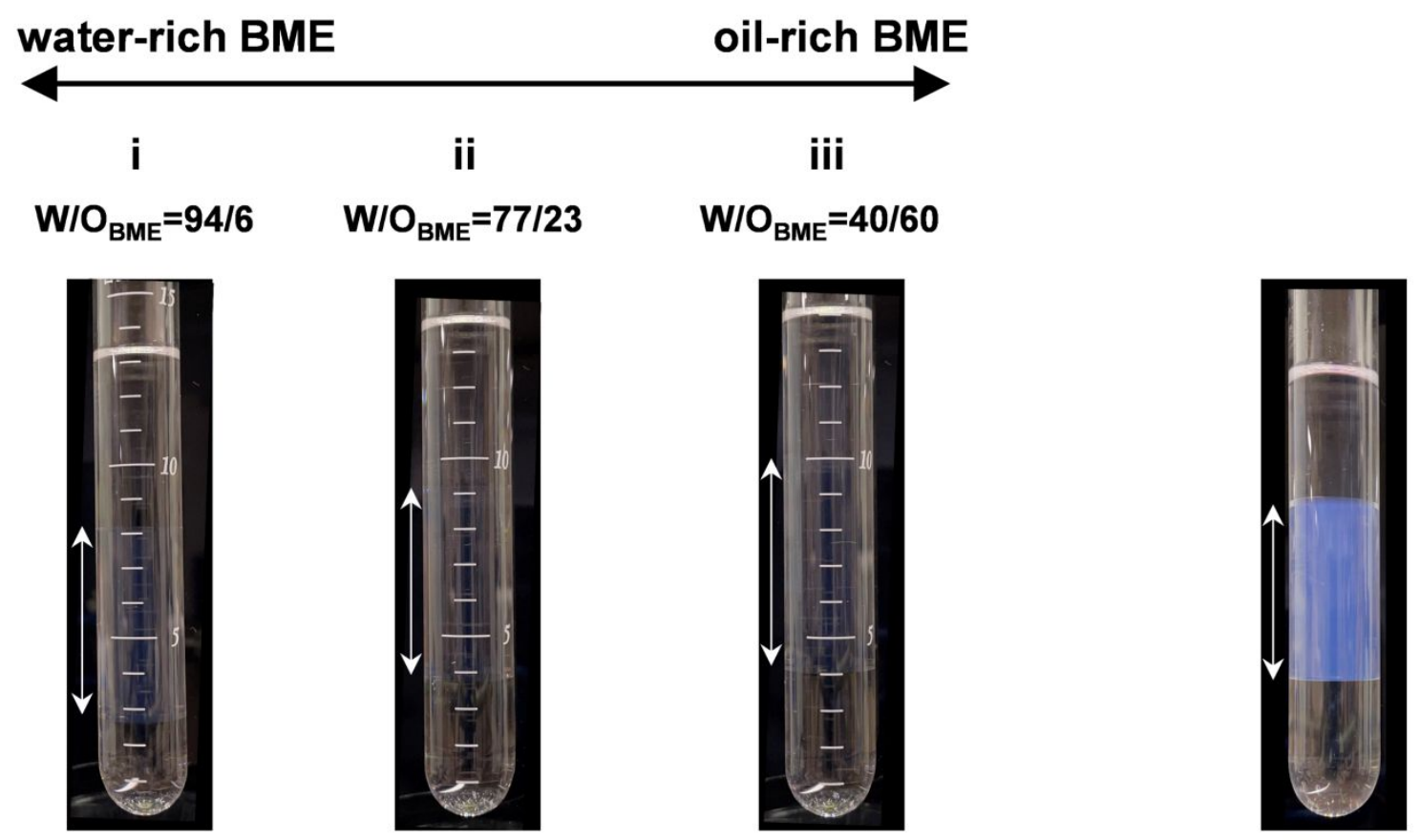

Figure S2. Photographs of the prepared BMEs. (a) Heptane-based BMEs with different $\mathrm{W} / \mathrm{O}_{\mathrm{BME}}$ values (the same samples as in Figure 1(b)) and (b) a toluene-based BME. The arrows represent middle (BME) phases. These photographs were taken under typical room lights. 


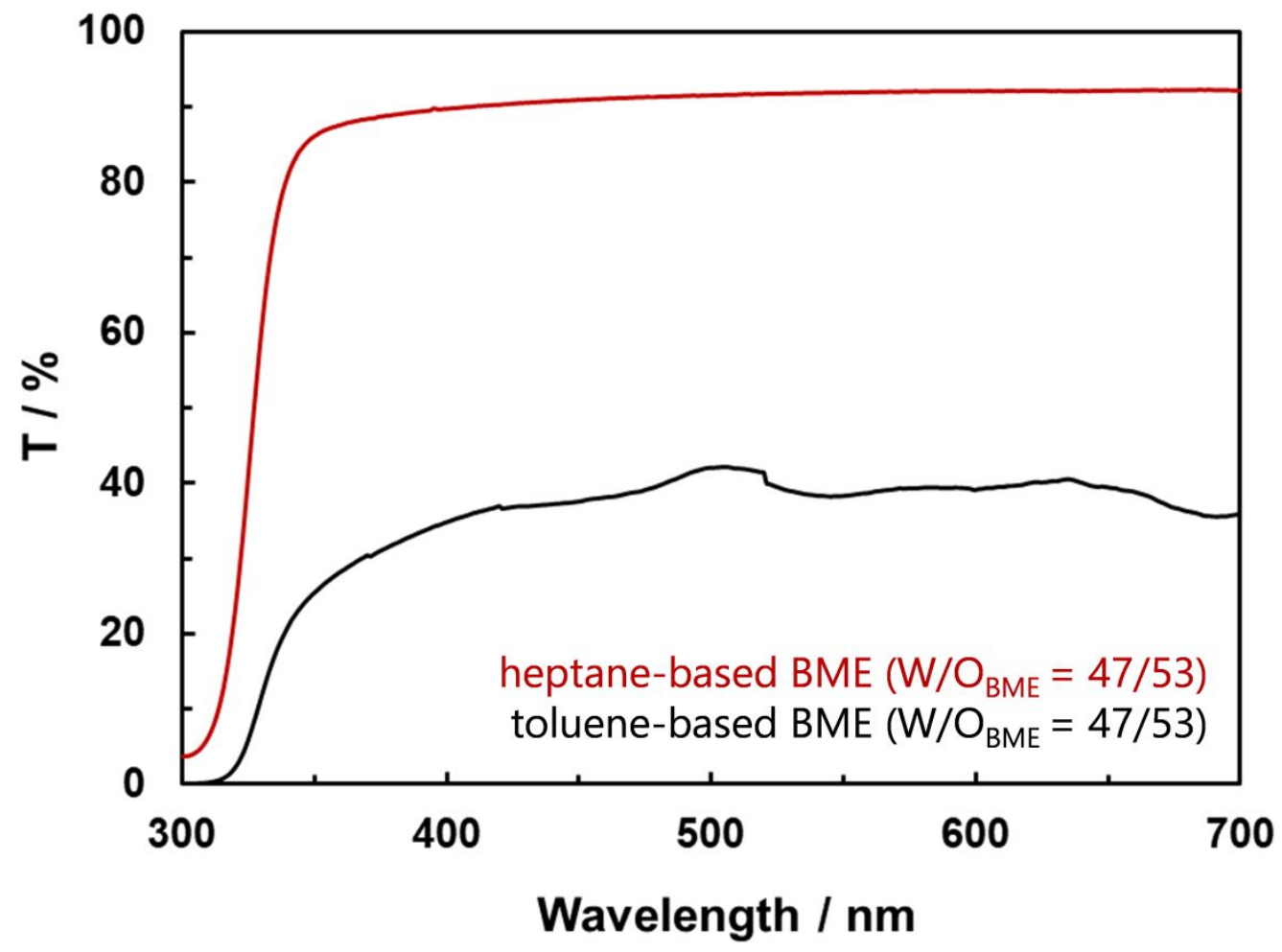

Figure S3. Transmittance (\%) of toluene-based BME (black) and heptane-based BME (red). 


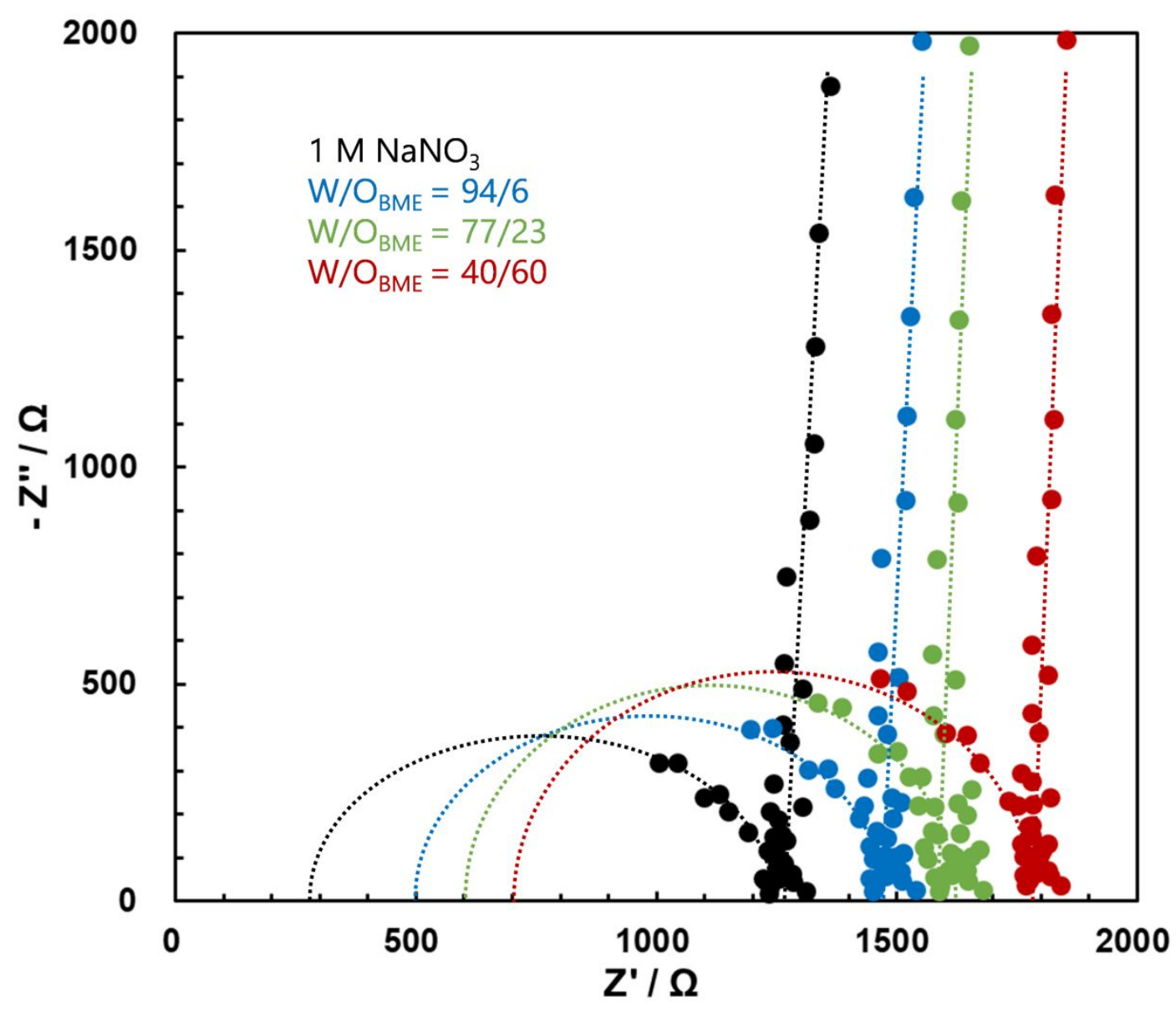

Figure S4. Typical Cole-Cole plots of F-nanocarbon film in a $1 \mathrm{M} \mathrm{NaNO}_{3}$ aqueous solution (black), and BME solutions with $\mathrm{W} / \mathrm{O}_{\mathrm{BME}}$ values of 94/6 (blue), 77/23 (green) and 40/60 (red). 


\section{A polarization-dependent fluorescence correlation spectroscopy (Pol-FCS) system}

Figure S5 shows the experimental setup of the Pol-FCS system we used for undertaking FCS measurements. This is similar to the experimental setup that we used in our previous study. ${ }^{1}$ An excitation laser with a wavelength of $488 \mathrm{~nm}$ was collimated and polarized by the lens $\mathrm{L}_{1}$ and the polarizer. The laser was reflected by a dichroic mirror (DM) (Di02-R488$25 \times 36$, Semrock, USA), and focused into sample solutions by a water immersion objective lens (Obj) (Uplan Apo 60x 1.20W, Olympus, Japan). The fluorescence emitted from the focal region of the objective lens was corrected by the same objective lens. The scattering light was eliminated by an emission filter (BLP01-488R-25, Semrock, USA). The fluorescence was focused by $L_{2}$ with a focal length of $150 \mathrm{~mm}$ and passed through a pinhole with a diameter of $25 \mu \mathrm{m}$ (1.01 Airy units). The fluorescence was collimated again by $\mathrm{L}_{3}$, split into two directions corresponding to its polarization by a polarizing beam splitter PBS. Each polarization component of the fluorescence was split by half mirrors $\mathrm{HM}_{1}$ and $\mathrm{HM}_{2}$, and finally detected by four photomultiplier tubes $\mathrm{D}_{1}-\mathrm{D}_{4}$ (H10682-210, Hamamatsu Photonics K.K., Japan). In this case, the polarization detected by $\mathrm{D}_{1}$ and $\mathrm{D}_{2}$ was parallel to the polarization of the excitation laser. In contrast, the polarization detected by $\mathrm{D}_{3}$ and $\mathrm{D}_{4}$ was perpendicular to the polarization of the excitation laser.

The electric pulse signal for the photon detection was output from each PMT. In this study, the signals from $\mathrm{D}_{1}$ and $\mathrm{D}_{4}$ were combined by an $\mathrm{OR}$ gate to reproduce a nonpolarized fluorescence signal. Similarly, the signals from $\mathrm{D}_{2}$ and $\mathrm{D}_{3}$ were also combined. The two combined signals were input into a hardware correlator (10CX220YU484I6G, APOLLO, Japan), and a cross-correlation function (CCF) was obtained. The time resolution of the CCF was set at $640 \mathrm{~ns}$ in this study. This measurement corresponds to a previously reported X-NN

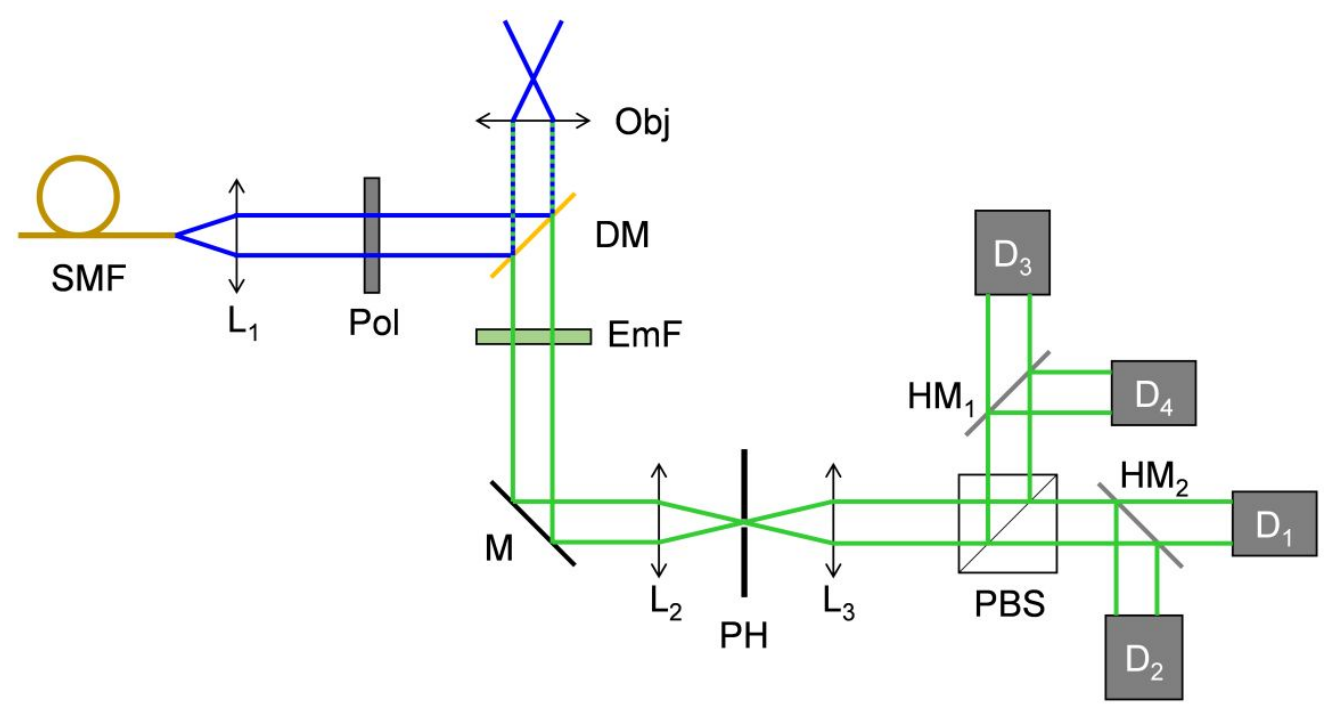

Figure S5. Experimental setup for FCS measurements. SMF, single mode optical fiber. L, lens. Pol, polarizer. Obj, objective lens. DM, dichroic mirror. EmF, emission filter. M, mirror. PH, pinhole. PBS, polarizing beam splitter. D, photomultiplier tube. 
condition, ${ }^{1}$ and the obtained CCF was similar to the autocorrelation function obtained with standard FCS instruments.

1. Yamamoto, J.; Matsui, A.; Gan, F.; Oura, M.; Ando, R.; Matsuda, T.; Gong, J. P.; Kinjo, M., Sci. Rep. 2021, 1110594. 